\title{
Olatu-kanal baten balioztatze esperimentala eta konputazionala
}

\section{(Experimental and computational validation of a wave flume)}

\author{
Iñigo Bidaguren*, Urko Izquierdo, Lander Galera, Iñigo Albaina, \\ Gustavo Adolfo Esteban, Ander Aristondo, Alberto Peña, Jesús María Blanco
}

Ingeniaritza Nuklearra eta Jariakinen Mekanika Saila, Bilboko Ingeniaritza Eskola, UPV/EHU

LABURPENA: BiMEP-Biscay Marine Energy Platform- eta Mutriku Wave Energy Plant-eko azpiegituretan itsas energiaren inguruko ikerkuntza egiten da, itsas baldintza errealetan. Bilboko Ingeniaritza Eskolako Fluidoen Mekanikako laborategian dagoen olatu-kanala $(12,5 \times 0,6 \times 0,7 \mathrm{~m}$, luzera $\times$ zabalera $\times$ sakonera $)$ azpiegitura horietan izaten diren baldintzak erreproduzitzeko gai da, eskala txikiago batean. Olatu-kanal horrek, pistoi motako olatu-sorgailu bat erabiliz, olatu monokromatiko eta pankromatiko mota desberdinekin lan egiteko aukera eskaintzen du. Ultrasoinuak erabiltzen dituzten zenbait zundak ur-gainazalaren desplazamendu bertikala neurtzen dute, eta tankearen amaieran kokatuta dagoen hondartzak, parabola-formadunak, olatuaren energia disipatzen du horren islapena murriztuz. «Reynolds Averaged Navier Stokes» (RANS) ekuazioetan oinarritutako zenbakizko modelo bat sortu da Star-CCM+ kode komertziala erabiliz, gainazal askean gertatzen diren fenomenoak simulatzeko. Zenbakizko modelo horren balioztatzea aurkezten da artikulu honetan, sakonera, olatu-altuera, uhin-luzera eta periodo desberdinak bateratuta eta egindako esperimentu sortarekin konparatuta. Emaitza guztiak fluxu potentzialaren teoriatik lortutako emaitza analitikoekin batera aztertu dira. Lan honetan aurkezten diren esperimentuek kanal horren eraginkortasunaren mugak ezartzen dituzte, olatuen sorkuntzari, hedapenari eta suntsipenari dagokienez. Etorkizunean egingo diren ikerkuntza-lanetako parametroak ezartzeko ere baliogarria izan da lan hau: egitura flotagarrien eta olatuen arteko interakzioa, olatu energiaren bihurgailuak eta ainguratze- eta amarradura-sistemak aztertuko dira.

HITZ GAKOAK: olatu-kanala, zenbakizko olatu-kanala, olatuen balioztatzea, BiMEP, itsas energia berriztagarriak.

\begin{abstract}
A wave flume of $12.5 \times 0.6 \times 0.7 \mathrm{~m}$ (length $\times$ width $\times$ height) able to reproduce the ocean conditions of the most representative research facilities in the Basque Country (BiMEP-Biscay Marine Energy Platform and Mutriku Wave Energy Plant) has been installed at the laboratory of Fluid Mechanics of the Faculty of Engineering in Bilbao. This new facility has the capacity of producing a wide range of monochromatic and panchromatic waves by a piston-type wavemaker. Several ultrasonic wave probes measure the surface elevation, and the wave energy is dissipated in a passive parabolic beach in order to diminish significantly the reflection along the flume. A numerical model based on Reynolds Averaged Navier Stokes (RANS) equations has been developed to represent the turbulence and Eulerian Volume of Fluid (VOF) unsteady approach in STAR-CCM+CFD code to track the evolution of the free surface. This numerical model has been validated with the corresponding experimental campaign covering a wide range of depths, wave heights, wavelengths and periods. The results are analysed together with the analytical solution coming from the potential flow theory. The experiments carried out in the present work establish the operational limits of the wave flume in terms of wave generation, propagation and extinction, defining the operational range of future experimental and computational campaigns where wave interaction with floating structures, wave energy converters and mooring systems will be studied.
\end{abstract}

KEYWORDS: wave flume, numerical wave flume, wave characterization, BiMEP, renewable marine energy.

* Harremanetan jartzeko / Corresponding author: Iñigo Bidaguren, Ingeniaritza Nuklearra eta Jariakinen Mekanika Saila, Bilboko Ingeniaritza Eskola, UPV/EHU. Euskal Herriko Unibertsitatea (UPV/EHU), S Torres Quevedo Enparantza 1 - 48013 Bilbo, Bizkaia. Euskal Herria. - i.bidaguren@ehu.eus - https://orcid.org/0000-0001-5180-6686.

Nola aipatu / How to cite: Bidaguren, Iñigo; Izquierdo, Urko; Galera, Lander; Albaina, Iñigo; Esteban, Gustavo Adolfo; Aristondo, Ander; Peña, Alberto; Blanco, Jesús María (2020). «Olatu-kanal baten balioztatze esperimentala eta konputazionala»; Ekaia, ale berezia 2020, 95-107. (https://doi.org/10.1387/ekaia.21107).

Jasoa: 24 iraila, 2019; Onartua: 11 azaroa, 2019

ISSN 0214-9001 - elSSN 2444-3255 / (c) 2020 UPV/EHU

Obra hau Creative Commons Atribución 4.0 Internacional-en

lizentziapean dago 
Iñigo Bidaguren, Urko Izquierdo, Lander Galera, Iñigo Albaina,

Gustavo Adolfo Esteban, Ander Aristondo, Alberto Peña, Jesús María Blanco

\section{SARRERA}

Energia-iturri berriztagarri eta jasangarrien erabilera dela eta, ardura handia dago gaur egun. Energia ekoizteko dauden aukera guztien artean gutxi batzuek bakarrik betetzen dute esanahi biak: berriztagarria (berriztu daitekeena) eta jasangarria (epe luzera erabili daitekeena iturria agortu gabe edo ingurumenari kalte larriak eragin gabe) [1]. 2018. urtean mundu osoan sortutako elektrizitatearen \% 26 iturri berriztagarrietatik etorri zen [2]. Energia berriztagarrien artean, itsas energiak (mareak, olatuak, itsas korronteak eta itsas aerosorgailuak) $42.619 \mathrm{GWh}$ sortu zituen 2016an, 19.252 MW potentzia instalatua izanik [3]. Sortutako energia horren \% 97 itsas aerosorgailuei dagokien arren, itsas olatuen energia ere etorkizun handiko aukera bat da $[4,5]$, aipatutako baldintzak, berriztagarritasuna eta jasangarritasuna, betetzen baititu. Olatu-energiaren potentziala erraldoia da, eta energia garbi, seguru eta epe luzerakoa bermatzen du. Azpimarragarria da nola herrialdeen, politikarien, industriaren eta, noski, zientziaren interesa handitzen ari den energia-iturri horren inguruan. Egun, garapen teknologikoan dago kokatuta arreta, olatu-energiaren bihurgailu (OEB) eraginkorrenaren bila [6].

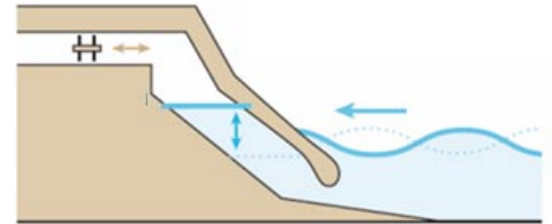

a)

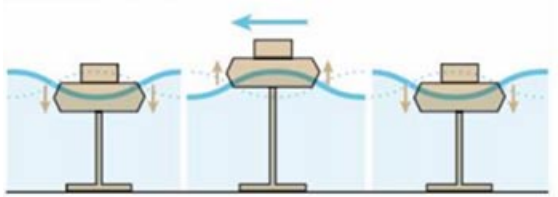

c)

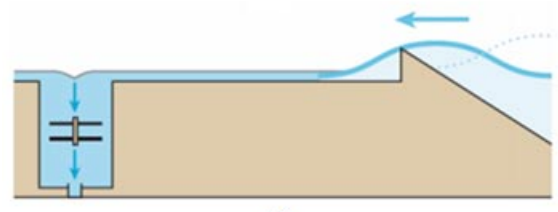

e)

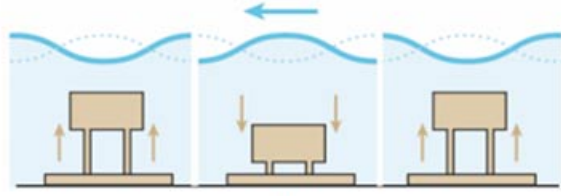

b)

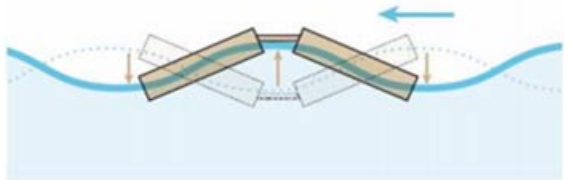

d)

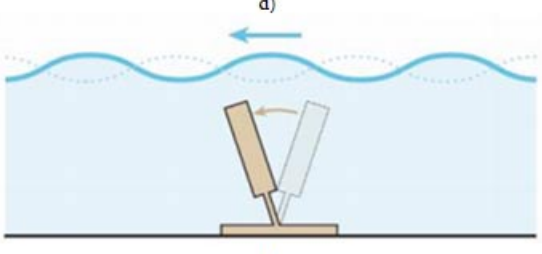

f)

1. irudia. Olatuen energia sortzeko oinarrizko sorgailuak: a) ur-zutabe oszilakorra, b) Arkimedesen efektua, c) Gorputz flotatzailea erreferentzia finkoarekin, d) Gorputz flotatzailea erreferentzia mugikorrarekin, e) Gainezkabidea, f) Egitura oszilakorra. 
Momentu honetan, printzipio fisiko ezberdinetan oinarritutako zenbait gailuren saiakuntzak (1:1 eskalan) egiten ari dira itsaso zabalean kokatutako instalazioetan [7]. Oinarri fisiko askoren artean, 1. irudian agertzen diren ideiak dira orokorrean erabiltzen ari direnak. Hala ere, oraindik lan handia dago, etengabea, laborategi-mailako ikerkuntzan gailu horien eraginkortasuna aztertzeko eta hobetzeko.

Itsas olatuez baliatzen diren energia-iturrien ikerkuntzan, teknologia-heldutasun maila (THM) baxuekin ari garenean (1 eta 4 artean), bi tresna erabiltzen dira batez ere: (i) simulazioak eta (ii) olatu-kanaletan edo -andeletan egindako saiakuntzak. Lehenengoek zenbakizko metodoak erabiltzen dituzte gertatzen diren fenomeno fisikoak gidatzen dituzten ekuazioak ebazteko. Nabarmendu beharra dago [8]-n proposatzen den teknologiaren garapenaren ibilbidea THM eta teknologia-jarduera mailaren (TJM) mendekotasuna. Beraz, [9]-n azaldu bezala, THM altuagoetara jo baino lehen, aurretik TJM altuagoa lortzea komenigarria izan daiteke, fidagarritasun handiko zenbakizko modeloak erabiliz, adibidez. Lan honetan fluidoen dinamika konputazionala (ingelesez, CFD) erabili da (aurrerago azalduko dira erabilitako xehetasun gehiago). Honela, lan-baldintza, itsaso-egoera eta gailu ezberdinen ia mugarik gabeko azterketa egin daiteke kostu erlatibo baxu batekin. Bigarrenek, hau da, olatu-kanaletan edo -andeletan egindako saiakuntzek, olatuak sortzeko eta haien garapena eta ondorioak aztertzeko gai diren instalazioak erabiltzen dituzte, non, orokorrean, eskala txikiago baten egiten diren saiakuntzak. Horretarako, Keulegan-Carpenter antzekotasuna ezartzen da normalean, itsasoan jarriko diren gailuen maketen eta olatuen arteko efektuak erreproduzitzeko. Antzekotasun-baldintza hori Froude-ren eta Strouhal-en zenbakien aldibereko antzekotasuna betetzearen baliokidea da. Bi tresnak (simulazioak eta olatu-kanaletako saiakuntzak) proiektuen hastapenetan erabiltzen dira, denbora zein dirua aurrezteko, eta diseinuaren inguruan egon daitezkeen zalantzak argitzeko. 1:1 eskalako portaera ikusi nahi denez, ordenagailuan sortutako modelo konputazionala eskala txikian egindako saiakuntza esperimentalekin balioztatzen da. Kostu aldetik oso eraginkorra da. Gerora, modeloa fidagarria denean, eskala handiago batan simulatzeko prest egongo gara, antzekotasun-baldintzak erabiliz [10]. Beraz, CFD teknikak erabili ahal izango dira OEB bat benetako eskalan aztertzeko, eta, horrela, gailuaren optimizazioan lan egin daiteke, haren fabrikaziora iritsi baino lehen.

Zenbait unibertsitatek eta ikerkuntza-zentrok eraiki dituzte beren laborategietan olatu-kanalak edota -andelak, itsasoko energia-iturri berriztagarrien garapena bultzatzeko; horrek instalazio mota hauen garrantzia adierazten du. Lisboako Instituto Superior Tecnico-n, adibidez, OEBetan erabiltzeko aire-turbina birradiala diseinatu eta frogatu dute. Ondoren, itsasoan benetako eskalan izan duen portaera BIMEPen [11] ikusi da 
Iñigo Bidaguren, Urko Izquierdo, Lander Galera, Iñigo Albaina, Gustavo Adolfo Esteban, Ander Aristondo, Alberto Peña, Jesús María Blanco

duela gutxi. Horrez gain, beste zenbait lan egin dira ur-zutabe oszilakorreko OEBen inguruan, [12-15] adibidez. Aalborg Unibertsitatean, olatuekin interakzioan jarduten duten egitura flotagarrien amarraduren diseinua, azterketa eta optimizazioa egin da [16]. Laborategi berean, OEB eta haize-turbina flotagarrien hidrodinamikaren modelizazio numeriko eta esperimentala ere egin da [17]. UCC-University College Cork, LABIMA Maritime Engineering Laboratory eta École Centrae Nantes-eko SEMREV ari dira, beste askoren artean, olatu-kanalak edota -andelak erabiltzen, energia berriztagarriaren sorkuntzan ikerkuntza-lan garrantzitsuak aurrera eramateko.

Artikulu honetan, Euskal Herriko Unibertsitateko Bilboko Ingeniaritza Eskolan, Fluidoen Mekanikako laborategian jarritako olatu-kanalaren karakterizazioa eta balioztatzea aurkeztuko dira. Hau da, alde batetik, kanal horretan olatu desberdinak egiteko ahalmenaren azterketa, Le Mehauté grafikoan deskribatzen diren limiteen arabera [18]; beste alde batetik, sortutako olatuak simulatzeko gai den modelo konputazionalaren balioztatzea, eta, azkenik, emaitza esperimental, konputazional eta teorikoen (olatu-teoriaren arabera) konparaketa hirukoitza. Beraz, lan honetan, kanalean sor daitezkeen olatuak simulatzeko ahalmena eta olatu-teoriarekin duten elkarrekikotasuna aurkezten dira.

\section{OLATU-KANAL ESPERIMENTALA (OKE)}

Kanalean olatuak sortzeko Delta-ASDA software komertziala erabiltzen da; Delta AC (ASDA-A2 seriekoa) serboeragingailua eta serbomotorra kontrolatzen ditu. Serbomotorra, $\mathrm{K}$ serieko eragingailu lineal bati dago lotuta (KM60-10), zeinek uretan partzialki murgilduta dagoen pala bati eragiten dion. Beraz, serbomotorraren mugimendu birakorra palaren desplazamendu lineal batean eraldatzen da, olatuak sortzeko erabiltzen den desplazamenduan, hain zuzen ere. Softwareak mugimendu azeleratu-dezeleratu sinusoidal bat agintzen dio palari olatuak sortzeko. Ur-gainazaleko mugimenduaren datuak jasotzeko bi zunda ultrasoniko erabiltzen dira (Pepperl+Fuchs UC500-L2-I-V15 modeloa), eta horiek, espresuki LABVIEW-n [19] sortutako programa batek kontrolatzen ditu. Programa horrek ur-gainazal askearen desplazamendua $(\eta[\mathrm{m}])$ denboraren mende (t [s]) jasotzen du, datuak jasotzen diren denbora-tartea $\Delta \mathrm{t}=10$ [ms] izanik. Deskribatutako ekipamenduaren ezaugarri nagusiak 1. taulan zehazten dira: 
1. taula. Serbomotorraren (goian), eragingailu linealaren (erdian) eta zunda ultrasonikoen (behean) ezaugarri nagusiak.

\begin{tabular}{|c|c|c|c|c|c|}
\hline \multicolumn{6}{|c|}{ ASDA-A2 serbomotorra (ECMA-C2080-7RS) } \\
\hline $\begin{array}{l}\text { Potentzia } \\
(\mathrm{kW})\end{array}$ & $\begin{array}{l}\text { Momentua } \\
(\mathrm{N} \cdot \mathrm{m})\end{array}$ & $\begin{array}{l}\text { Momentu maximoa } \\
\qquad(\mathrm{N} \cdot \mathrm{m})\end{array}$ & Abiadura (bira/min) & $\begin{array}{l}\text { Abiadura } \\
\text { maximoa } \\
\text { (bira/min) }\end{array}$ & $\begin{array}{c}\text { Errotorearen } \\
\text { inertzi } \\
\text { momentua } \\
\left(\cdot 10^{-4} \mathrm{~kg}-\mathrm{m}^{2}\right)\end{array}$ \\
\hline 0,75 & 2,39 & 7,16 & 3000 & 5000 & 1,13 \\
\hline \multicolumn{6}{|c|}{ Eragingailu lineala (KM60-10) } \\
\hline $\begin{array}{l}\text { Markoaren } \\
\text { neurria } \\
(\mathrm{mm})\end{array}$ & $\begin{array}{l}\text { Torloju } \\
\text { aitzinamendua } \\
\quad(\mathrm{mm})\end{array}$ & Indar maximoa $(\mathrm{kN})$ & $\begin{array}{l}\text { Abiadura, bira/min } \\
\text { maximoetara }(\mathrm{mm} / \mathrm{s})\end{array}$ & $\begin{array}{c}\text { Karga } \\
\text { dinamikoa } \\
(\mathrm{kN})\end{array}$ & $\begin{array}{l}\text { Momentu } \\
\text { maximoa } \\
\text { sarreran } \\
(\mathrm{N} \cdot \mathrm{m})\end{array}$ \\
\hline 60 & 10 & 3,0 & 833 & 6,8 & 6 \\
\hline \multicolumn{6}{|c|}{ Zunda ultrasonikoak (UC500-L2-I-V15) } \\
\hline $\begin{array}{l}\text { Balio-tartea } \\
\quad(\mathrm{mm})\end{array}$ & $\begin{array}{l}\text { Eremu itsua } \\
(\mathrm{mm})\end{array}$ & Bereizmena (mm) & $\begin{array}{l}\text { Erantzun-atzerapena } \\
\qquad(\mathrm{ms})\end{array}$ & $\begin{array}{l}\text { Tentsioa } \\
\text { (V DC) }\end{array}$ & $\begin{array}{l}\text { Irteera mota } \\
\qquad(\mathrm{mA})\end{array}$ \\
\hline $35-500$ & $0-35$ & Ebaluazio-tartea/3200 & 50 & $10-30$ & $4-20$ \\
\hline
\end{tabular}

Delta-ASDA softwarea erabiliz, palaren anplitudea $\left(A_{p}[m]\right)$ eta periodoa ( $\mathrm{T}[\mathrm{s}]$ ) zehaztu daitezke palaren desplazamendua sortzeko. Informazio horrekin eta erabilitako ur-sakonerarekin, sortutako olatuen ezaugarriak bereiz daitezke: olatuaren abiadura $(\mathrm{c}[\mathrm{m} / \mathrm{s}])$, uhin-luzera $(\lambda[\mathrm{m}])$, periodoa $(\mathrm{T}[\mathrm{s}])$ eta altuera $(\mathrm{H}[\mathrm{m}])$. Bai laborategiko esperimentuak bai ordenagailuan egindako simulazioak ur-sakonera $(\mathrm{h}[\mathrm{m}])$ desberdinekin egin dira $(\mathrm{h}[\mathrm{m}]=0,3,0,4$ eta 0,5$)$, pistoi motako olatu sorgailua anplitude eta periodo desberdinekin lan eginez $\left(1,0<\mathrm{A}_{\mathrm{p}}[\mathrm{mm}]<54,0\right.$ eta $0,87<\mathrm{T}[\mathrm{s}]<2,02$, hurrenez hurren).

Esperimentuak egiteko erabilitako OKEaren luzera 12,5 m da, zabalera $0,60 \mathrm{~m}$ eta sakonera $0,70 \mathrm{~m}$. Egitura altzairu herdoilgaitzez egindakoa da eta kanalaren paretak tenplatutako kristalezkoak. Lehen zunda olatu-sorgailutik 6,0 m-ra kokatuta dago; puntu horretan olatua guztiz garatuta dagoela onar daiteke. Hurrengo zunda aurrekotik $30 \mathrm{~cm}$-ra jarri da, [20]-n deskribatzen diren irizpideen arabera. Kanala hiru atal desberdinetan bereiz daiteke: olatuen sorgailua, olatuen hedapen-eremua eta olatuen suntsipen-eremua. Azken hau forma parabolikoa eta 1,5 m-ko luzera dituen hondartza bat da, eta bere altuera eta angelua doitzeko aukera ematen du. 
Iñigo Bidaguren, Urko Izquierdo, Lander Galera, Iñigo Albaina,

Gustavo Adolfo Esteban, Ander Aristondo, Alberto Peña, Jesús María Blanco
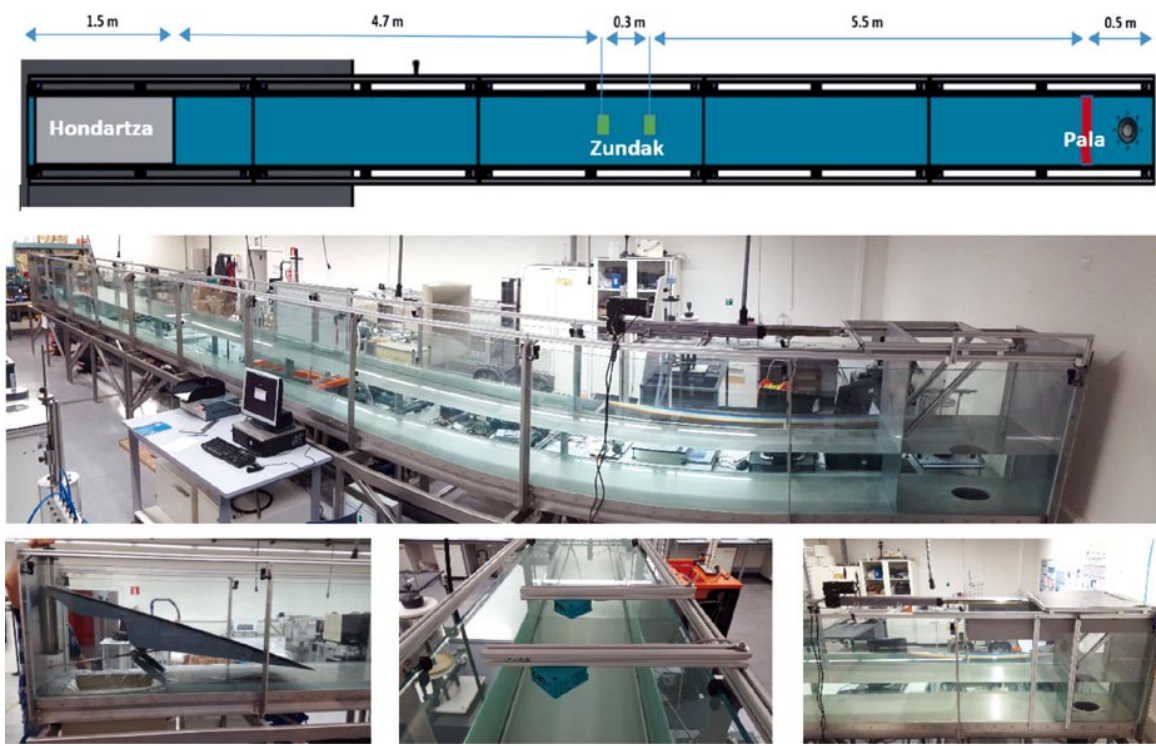

2. irudia. Goian OKEaren eskema goitik ikusita. Erdian: OKEaren ikuspegi orokorra. Behean (ezkerretik eskuinera): olatu-suntsipenerako sistema, zunda ultrasonikoak eta pistoi-motako olatu-sorgailua.

\section{ZENBAKIZKO OLATU-KANALA (ZOK)}

Efektu fisikoak bi dimentsioko (2D) modelo konputazional batekin simulatu dira (softwarea: STAR CCM+ v12.06), sakoneraren arabera neurri desberdinetako elementuak erabiltzen dituen sare bat erabiliz. Sarearen hiru bolumen bereizi dira: olat-sorgailuaren inguruko bolumena, hondartzaren ingurukoa eta ur-gainazal askearen ingurukoa. Eremu horietako fisika hobeto zehazteko zelda txikiagoak erabili dira. Palaren mugimendua simulatzeko eta gainazal askearen mugimendua jasotzeko erabiltzaileak sortutako funtzioak programatu dira.

ZOKak eta OKEak geometria berdin-berdina dute, OKEaren simulazioa egin ahal izateko eta ZOKaren balioztatzea lortzeko (ikusi 3. irudia). Simulazioa egiteko erabili diren modelo fisikoen artean honakoak aipatu beharra dago: k- $\varepsilon$ turbulentzia-modeloa, denborarentzako eskema inplizitu iragankorra eta aire- eta ur-faseen elkarrekintza kontuan hartzen duen Volume of Fluid (VOF) modeloa [21]. Honekin batera, aztertutako kasu bakoitzaren arabera, sarea egokitu da. Esan bezala, palan, gainazal askean eta hondartzan elementuen tamaina txikiagoa erabili da $(2,7,3,3$ eta $1,5 \mathrm{~mm}$ koa, 0,3, 0,4 eta 0,5 m-ko sakoneretarako, hurrenez hurren). Beste eremuetan elementuen tamaina handiagoa izan da. Horrela, 0,3 m-ko sakone- 
ran, sareak 328.297 elementu ditu; 0,4 m-koan, 389.292, eta 0,5 m-koan, 788.005 .

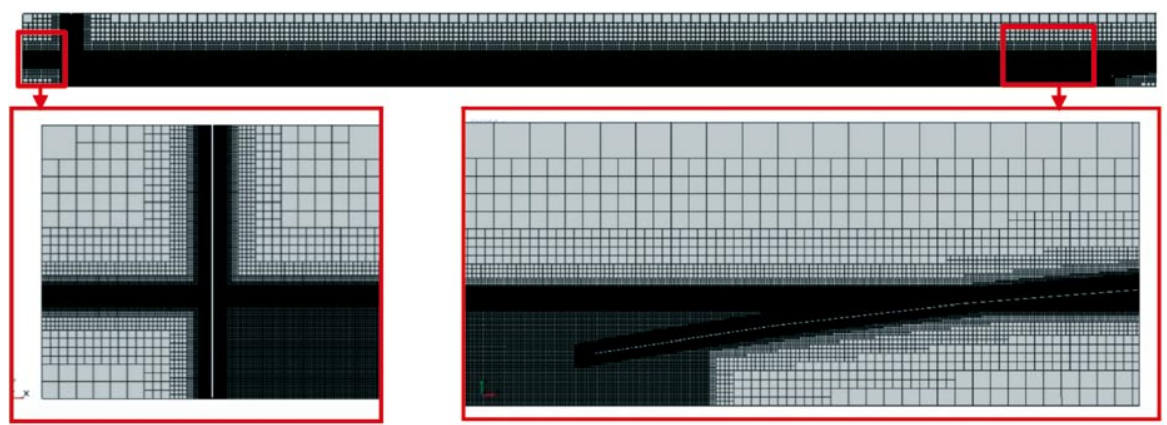

3. irudia. Goian: ZOKaren ikuspegi orokorra, $\mathrm{h}=0,3 \mathrm{~m}$-rako sare konputazionala. Behean: garrantzizko eremuen xehetasuna: pala (ezkerrean) eta hondartza (eskuinaldean).

Olatu-kanalaren atalik garrantzitsuenetariko bat pala denez, honen inguruko sarearen azterketa sakonagoa egin da. Gainazal horren y+-a begiratu da, eta 2. taulan aurkezten diren balioak lortu dira, palarekin kontaktuan dagoen fluidoaren arabera (airea, ura, gainazal askea):

2. taula. Hormaren y+ balioen tarteak.

\begin{tabular}{lc}
\hline \multicolumn{2}{c}{ Hormaren y+ balioen tarteak } \\
\hline Elementuen itxura erlazioa & $0,78-0,95$ \\
Hormaren y+ (Airearekin) & $0,05-1,00$ \\
Hormaren y+ (Urarekin) & $0,7-4,0$ \\
Hormaren y+ (Gainazal askearekin) & $4-18$ \\
\hline
\end{tabular}

\section{EMAITZAK}

Egindako esperimentu sorta Le Méhauté-ren grafikoan oinarrituz zehaztu da. BiMEP eta IH Cantabriak [22]-n argitaratu duten bezala, BiMEP itsas zabaleko instalazioan izaten diren itsas baldintzak Airy-k garatutako teoria lineala [23] eta Stokes-ek garatutako teoria ez-lineala [24] erabiliz deskriba daitezke; kasu bietan, ur-sakonera ertaineko eta handiko eremuetan. Hala ere, lan honetan aurkezten diren emaitzek ez dituzte BiMEPeko itsas baldintzak bakarrik betetzen, baizik eta eremu lineal eta ez-linealaren barruan gertatzen diren beste itsas baldintza batzuk ere. Behin esperimentu baten ur sakonera finkatzen denean, $T$ eta $A_{p}$ kalkulatzen dira, 
Iñigo Bidaguren, Urko Izquierdo, Lander Galera, Iñigo Albaina,

Gustavo Adolfo Esteban, Ander Aristondo, Alberto Peña, Jesús María Blanco

horiek baitira esperimentu bakoitzeko aldagaiak. Bai esperimentalki zein simulazioetan lortutako ur-gainazalaren desplazamenduko emaitzak denboraren mendekoak dira. 4. irudian, OKEa eta ZOKa erabiliz lortutako gainazal askearen desplazamenduaren konparaketa aurkezten da.
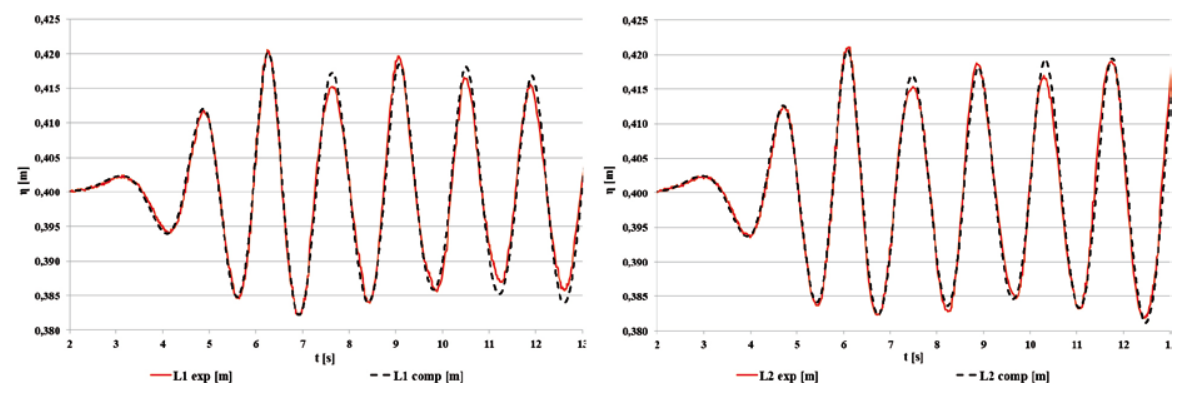

4. irudia. Esperimentuan eta simulazioan, zundek jasotako gainazal askearen desplazamenduaren konparaketa. Ezkerrean, lehengo zunda (L1), eta eskuinean, bigarrena (L2). Baldintzak: $\mathrm{h}=0,40 \mathrm{~m}, \mathrm{~A}_{\mathrm{p}}=39,9 \mathrm{~mm}$ eta $\mathrm{T}=1,43 \mathrm{~s}$.

4. irudian ikus daitekeen bezala, OKEa eta ZOKa erabiliz lortu diren emaitzak bat datoz bata bestearekin. Ez da desfaserik atzematen haien artean, eta hori adierazgarri da periodoa eta hedapen-abiadura konstante mantendu direla. Beraz, emaitza arrakastatsuak lortu dira gainazal askearen desplazamenduari dagokionez. Datu guztiak Matlab R2019a erabiliz prozesatu dira. Gainazal askearen desplazamenduaren profilak teoria linealaren edo Stokes-en (2. mailakoa) teoriaren arabera doituak izan dira, eta olatuaren hedapen abiadura $\mathrm{c}, \lambda$, $\mathrm{T}$ eta $\mathrm{H}$ lortu. Teoria horiek honela definitzen dira:

$$
\begin{aligned}
& \eta(x, t)=\frac{H}{2} \cos (k x-w t) \\
& \eta(x, t)=\frac{H}{2} \cos (k x-w t)+k\left(\frac{H}{2}\right)^{2} \frac{1}{\tanh (k h)}\left(1+\frac{3}{2 \sinh ^{2}(k h)}\right) \cos (2 k x-2 w t)
\end{aligned}
$$

Olatu-profil bakoitza zehazten duten parametroak 3. taulan bilduta daude, non $\mathrm{H}, \mathrm{T}, \lambda$ eta c-ren balioztatzearen errore erlatiboa eta errore erlatibo teorikoa horrela definitzen diren:

$$
\begin{aligned}
& x_{\text {errorea }}=\frac{X_{\text {esp }}-X_{\text {konp }}}{X_{\text {esp }}} \cdot 100, \\
& x_{\text {errorea }}=\frac{X_{\text {teor }}-X_{\text {konplesp }}}{X_{\text {teor }}} \cdot 100 .
\end{aligned}
$$


Olatu-kanal baten balioztatze esperimentala eta konputazionala

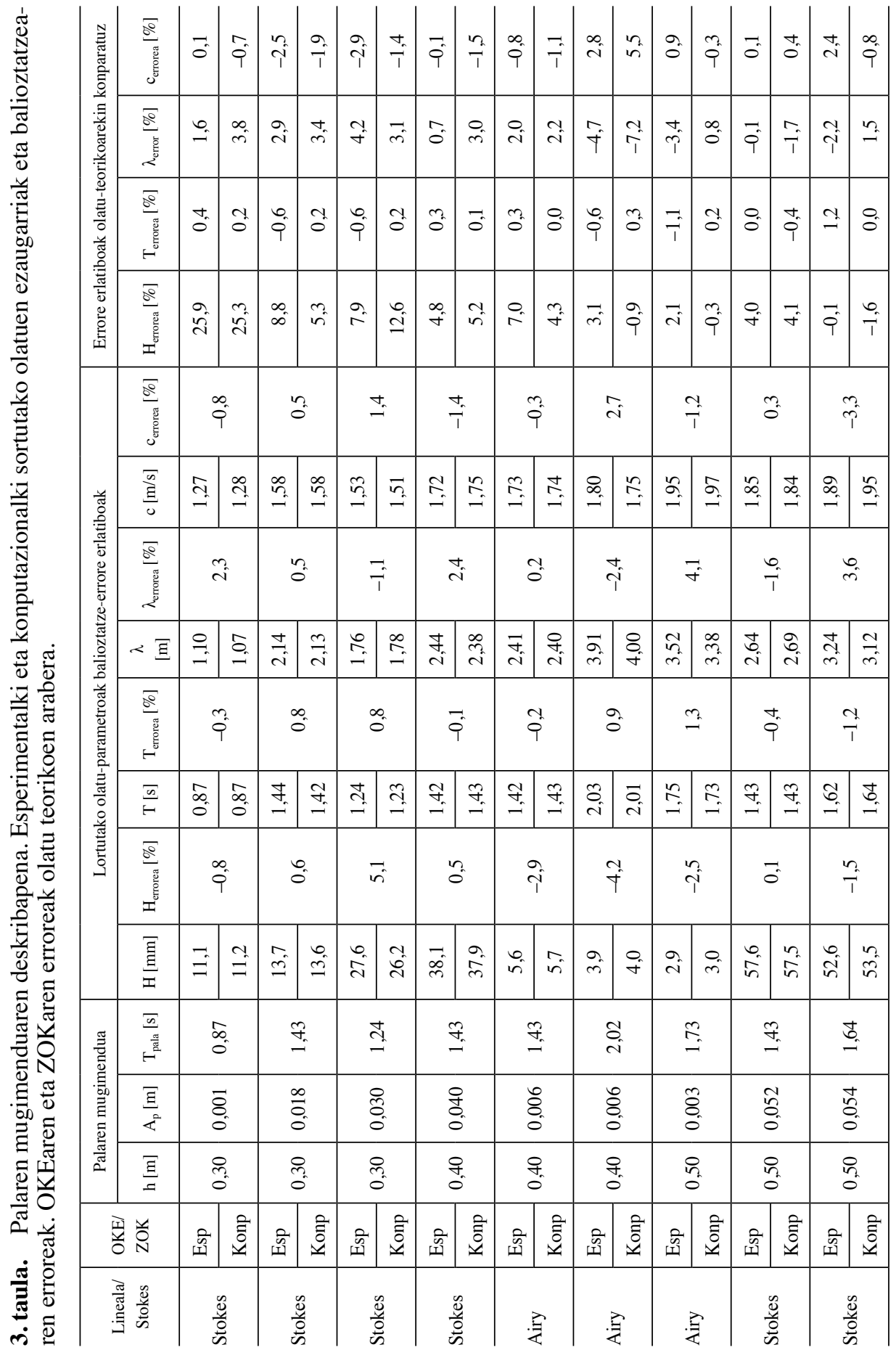


Iñigo Bidaguren, Urko Izquierdo, Lander Galera, Iñigo Albaina,

Gustavo Adolfo Esteban, Ander Aristondo, Alberto Peña, Jesús María Blanco

3. taulan ikusten den bezala simulazio eta esperimentuen arteko emaitzen korrelazioa oso ona da. Esperimentuen balioztatzearen erroreak \% 5 baino txikiagoak dira; aldiz, errore nabarmenak agertu dira olatu-altuera teorikoekin konparatuta. Hori aurreko lan batean ere [25] hauteman zuten egileek. Taulan agertzen diren parametroak, periodo txikiak, olatu-altuera txikiak edo itsaso-baldintzak sakonera handiko olatuen eremuaren mugan $(\mathrm{h} / \lambda>0,5)$ neurtzen dira orokorrean.

Behin parametro guztiak kalkulatuta, seinale teorikoa marraztea posible da, (2) eta (3) ekuazioen arabera. Hauek seinale esperimentalarekin eta konputazionalarekin aldera daitezke 4. irudian ikus daitekeen moduan.
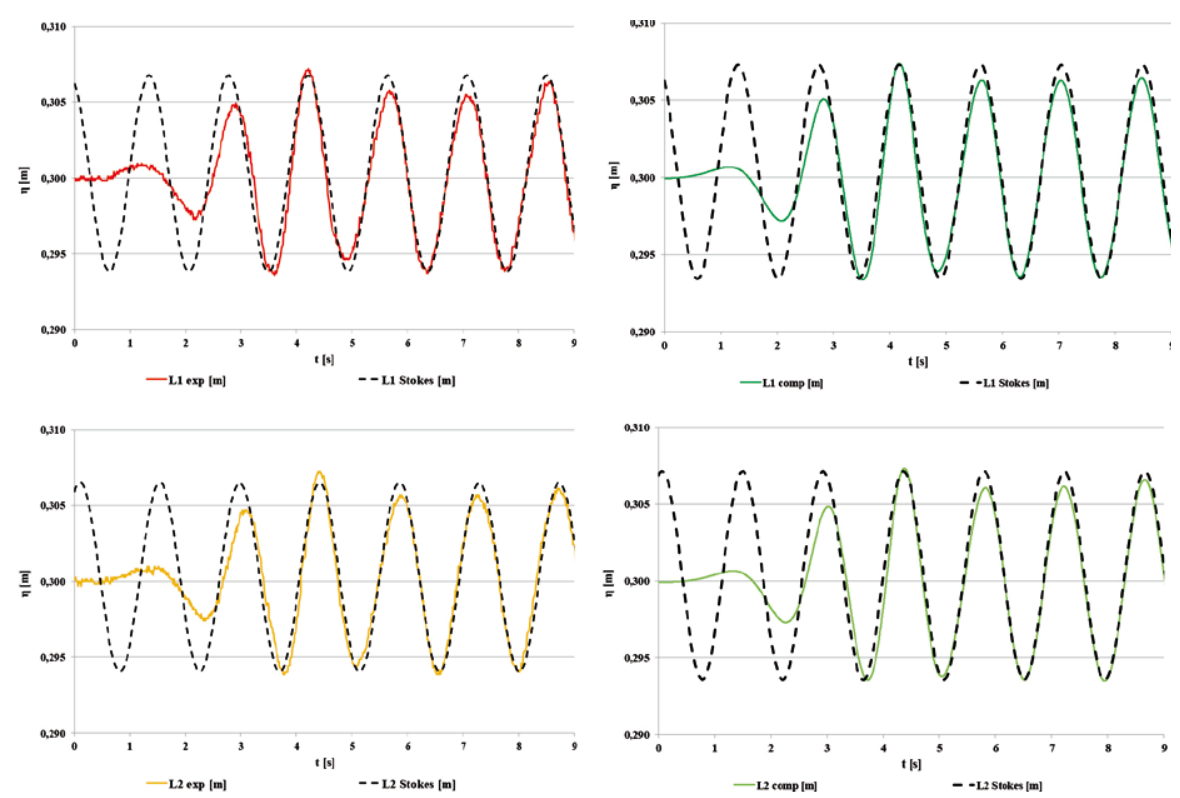

5. irudia. Esperimentalki (ezkerra) eta konputazionalki (eskuina) neurtutako gainazal askearen bilakaerak, L1 (goian) eta L2 (behean), bigarren mailako (Stokes) adierazpenarekin doituak. Baldintzak: $\mathrm{h}=0,30 \mathrm{~m} \mathrm{~A}_{\mathrm{p}}=17,7 \mathrm{~mm}$ eta $\mathrm{T}=1,43 \mathrm{~s}$.

6. irudian T-ren eta c-ren emaitzak aurkezten dira $\lambda$-ren mende, esperimentalki eta zenbakizko simulazioetatik lortutako datuekin, aipatutako Airy-ren eta Stokes-en olatu-teorietatik, $\lambda$, $T$ eta $h$ erlazionatuz:

$$
\begin{aligned}
& \lambda=\frac{g T^{2}}{2 \pi} \tanh \left(\frac{2 \pi h}{\lambda}\right), \\
& c=\frac{g T}{2 \pi} \tanh \left(\frac{2 \pi h}{\lambda}\right)=\frac{\lambda}{T}
\end{aligned}
$$



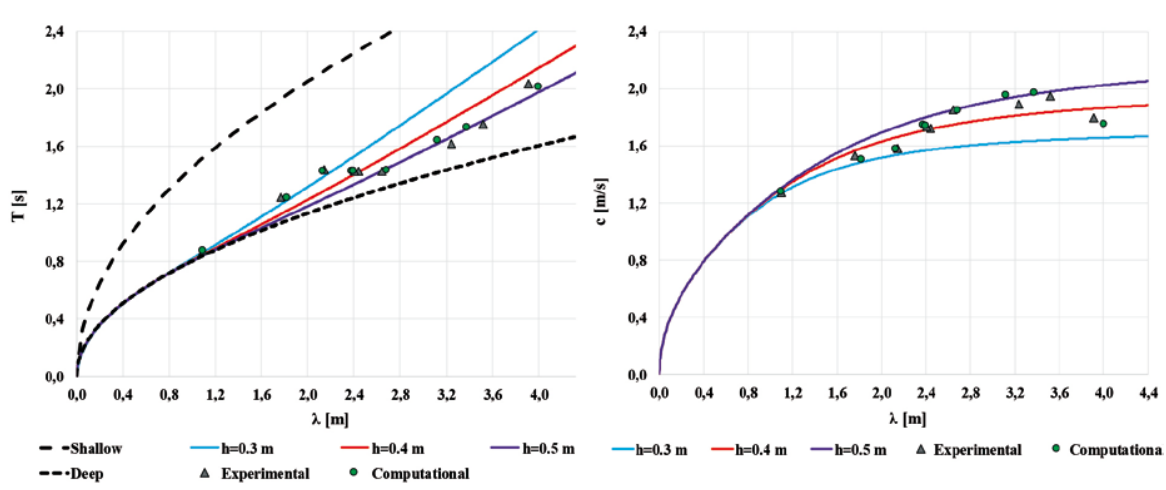

6. irudia. Emaitza esperimentalak eta konputazionalak olatuen uhin-luzeraren mende, periodoaren arabera (ezkerrean) eta hedapen-abiaduraren arabera (eskuinean).

6. irudian ikusten denez, OKEaren eta ZOKaren arteko emaitzak oso antzekoak dira. Horrez gain, emaitza teorikotik oso hurbil agertzen dira.

\section{ONDORIOAK}

Euskal Herriko Unibertsitatean, Bilboko Ingeniaritza Eskolako Jariakinen Mekanikako laborategian instalatuta dagoen olatu-kanala itsaso-baldintza desberdinetan esperimentuak egiteko diseinatuta dago. Orokorrean olatuekin eta itsasoarekin elkarrekintza duten egiturak eta gailuak eskala txikian probatzeko dago diseinatuta. Itsas energia berriztagarriei dagokienez, Euskal Herrian badago non probatu eta ikertu, itsasoaren baldintza errealetan, itsas energiaren bihurgailuak. Lan honetan aurkezten den olatu-kanalak horrelako egituretan izaten diren itsas baldintzak erreproduzitu ditzake, laborategi-eskalan. Ezaugarri horiek instalazio paregabe bihurtzen dute olatu-kanala THM baxua duten eskala txikiko prototipoak ikertzeko, probatzeko eta ondorioak lortzeko.

Artikulu honetan aurkeztu diren emaitzek kanalak esperimentu desberdinek behar dituzten baldintzetara egokitzeko duen gaitasuna egiaztatzen dute. Honez gain, esperimentu horiekin, simulazioetan errepikatzeko ahalmena erakusten da; horrek itsas energia berriztagarriekin erlazioa duten azterketa anitz egiteko aukera ematen du.

Etorkizun hurbilean olatu-kanalaren hondartzaren islapena aztertuko da, eta haren koefizienteak lortuko, M. Isaacson et al.-ek [20]-n azaltzen duten moduan. Islapenaren azterketa abiapuntu bat izango da beste ikerkuntza batzuk egiteko: flotatzen duten egituren hidrodinamika edo haien ainguratze-sistemak, besteak beste. 
Iñigo Bidaguren, Urko Izquierdo, Lander Galera, Iñigo Albaina,

Gustavo Adolfo Esteban, Ander Aristondo, Alberto Peña, Jesús María Blanco

\section{ESKER ONAK}

Egileek Eusko Jaurlaritzari eskertu nahi diote KK-2016/00031 proiektuan jasotako babesa eta IT1314-19 ikerkuntza-taldea sustatzea. UPV/ EHUri ere eskerrak eman nahi dizkiote, PES17/25 proiektuagatik eta IZOSGI SGIker sailari eskaini dion laguntza guztiagatik. Eskerrak, baita ere, Europako erakundeek emandako dirulaguntzagatik (ERDF eta ESF) eta Davidi (Mecánica Moderna S.A.).

\section{BIBLIOGRAFIA}

[1] DINCER I. 2000. «Renewable energy and sustainable development: a crucial review». Renewable and Sustainable Energy Reviews», 4, 157-175.

[2] ENERDATA, 2019. «Global Energy Statistical Yearbook». Enerdata.

[3] IRENA (International Renewable Energy Agency), 2018. «Capacity and Generation (Statistics Time Series)».

[4] LENEE-BLUHM P., PAASCH R., ÖZKAN-HALLER H.T. 2011. «Characterizing the wave energy resource of the US Pacific Northwest». Renewable Energy, 36 , 2106-2119.

[5] BARSTOW S, GUNNAR M, MOLLISON D, CRUZ J. 2008. The wave energy resource. Cruz J. (eds.) Ocean Wave Energy. Green Energy and Technology (Virtual Series). Springer, Berlin, Heidelberg.

[6] FALNES J. 2007. «A Review of Wave-Energy Extraction». Marine Structures, 20, 185-201.

[7] FALCÃO AFO. 2010 «Wave Energy Utilization : A Review of the Technologies». International Journal of Marine Energy, 14, 899-918.

[8] WEBER J. 2012. «WEC Technology Readiness and Performance Matrixfinding the best research technology development trajectory». Int. Conf. Ocean Energy, Dublin Ireland.

[9] PENALBA M, DAVIDSON J, WINDT C, RINGWOOD JV. 2018. «A highfidelity wave-to-wire simulation platform for wave energy converters: Coupled numerical wave tank and power take-off models». Applied energy, 226, 655-669.

[10] FALCÃO AFO eta HENRIQUES JCC. 2014. «Model-Prototype Similarity of Oscillating-Water-Column Wave Energy Converters». International Journal of Marine Energy, 6, 18-34.

[11] CARRELHAS AAD,GATO LMC, HENRIQUES JCC et al. 2019. «Test Results of a $30 \mathrm{~kW}$ Self-Rectifying Biradial Air Turbine-Generator Prototype». Renewable and Sustainable Energy Reviews, 109, 187-198.

[12] RIBEIRO S, SILVA E, GOMES RPF et al. 2016. «Hydrodynamic Optimization of the UGEN: Wave Energy Converter with U-Shaped Interior Oscillating Water Column». International Journal of Marine Energy, 15, 112126. 
[13] HENRIQUES JCC, LOPES MFP, GOMES RPF et al. 2012 «On the Annual Wave Energy Absorption by Two-Body Heaving WECs with Latching Control». Renewable Energy, 45, 31-40.

[14] LOPES BS, GATO LMC, FALCÃO AFO et al. 2018. «Test Results of a Novel Twin-Rotor Radial Inflow Self-Rectifying Air Turbine for OWC Wave Energy Converters». Energy. 170 p.869-879.

[15] HENRIQUES JCC, GATO LMC, GOMES RPF et al. 2015. «Latching Control of a Floating Oscillating-Water-Column Wave Energy Converter». Renewable Energy. 90, 229-41.

[16] ZANUTTIGH B, ANGELELLI E eta KOFOED JP. «Effects of Mooring Systems on the Performance of a Wave Activated Body Energy Converter». Renewable Energy, 57, 422-431.

[17] MARTINELLI L, ZANUTTIGH B eta KOFOED JP. 2011. «Selection of Design Power of Wave Energy Converters Based on Wave Basin Experiments». Renewable Energy. 36, 3124-3132.

[18] LE MÉHAUTÉ, BERNARD. 1976. An Introduction to Hydrodynamics and Water Waves. Springler-Verlag, USA.

[19] National Instruments. LabVIEW 2016 (64-Bit) - English. 2016, http://www. ni.com/download/labview-development-system-2016/6055/en/

[20] ISAACSON M. 1991. «Measurement of Regular Wave Reflection». Journal of Waterway Port Coastal and Ocean Engineering, 117, 553-569.

[21] User Guide. STAR-CCM + ${ }^{\circledR}$ Documentation. 2015.

[22] BIMEP and IH Cantabria. Metocean Analysis of BiMEP for Offshore Design. March, 2017.

[23] AIRY GB. 1845. «Tides and Waves». Enciclopedia Metropolitana, 5, 241396.

[24] STOKES, G. 1847. «On the Theory of Oscillatory Waves». Transaction of the Cambridge Philosophical Society, 8, 441-455.

[25] IZQUIERDO U, ESTEBAN GA, BLANCO JM et al. «Experimental Validation of a CFD Model Using a Narrow Wave Flume». Applied Ocean Research, 86, 1-12.

[26] ROBERT GD eta ROBERT AD. 1991. Water Wave Mechanics for Engineers and Scientists Advanced Series on Ocean Engineering. World Scientific Publishing Co. Pte. Ltd, Cornell University, USA. 